\title{
DIAGNÓSTICO DE SÍNDROME DE GARDNER ATRAVÉS DE MANIFESTAÇÕES ORAIS
}

Luiz Felipe Gomes dos SANTOS, Joanna Gomes da CONCEIÇÃO, Maria Eliza Barbosa RAMOS, Mônica Simões ISRAEL

A síndrome de Gardner é uma desordem rara, autossômica dominante, com quase 100\% de penetrância. É caracterizada por polipose intestinal familial, além de achados clínicos envolvendo pele, tecidos moles, retina, sistema esquelético e dentes. Cerca de 90\% dos pacientes mostram anormalidades esqueléticas, sendo os osteomas as mais comuns. As áreas mais comumente envolvidas são o crânio, os seios paranasais e a mandíbula. Geralmente os osteomas são observados durante a puberdade e precedem o desenvolvimento de qualquer sintoma dos pólipos intestinais. Os indivíduos portadores desta desordem podem apresentar anormalidades dentárias, tais como prevalência aumentada de odontomas, dentes supranumerários e impacção dentária. O objetivo deste trabalho é relatar o caso clínico de um paciente de quatorze anos, sexo feminino, que se apresentou a um serviço de estomatologia queixando-se de retenção prolongada dos incisivos centrais decíduos. A paciente foi submetida a exame radiográfico que evidenciou imagens sugestivas de múltiplos odontomas e osteomas nos ossos maxilares. A paciente foi orientada a realizar exames complementares para pesquisa de pólipos intestinais, que evidenciou o diagnóstico de Síndrome de Gardner. Um criterioso exame bucal foi de fundamental importância no estabelecimento do diagnóstico dessa síndrome e na prevenção de câncer intestinal. 